\title{
ИСПОЛЬЗОВАНИЕ ПОКАЗАТЕЛЕЙ ЦИТИРОВАНИЯ: ПРОБЛЕМЫ И ПОСЛЕДСТВИЯ
}

\author{
Никонова М.А.
}

В последнее время для оченки научного вклада ученых широкую популярность получили библиометрические показатели - индексы циитирования (индекс Хирша и импакт-фактор), которые кроме удобства (из-за чего они были выбраны) имеют и иельіи ряд недостатков. Их активное использование со временем может привести к существенным проблемам. Данная статья посвящена анализу проблем, которые могут возникнуть при активном использовании библиометрических показателей.

DOI: $10.20537 /$ mce2020econ07

Показатели цитирования в последнее время стали очень популярны в нашей стране. Их используют (в качестве одного из показателей) для оценки деятельности вузов, научных институтов и отдельных исследователей, что, на первый взгляд, является довольно простым и удобным способом оценки. Однако у этого метода есть довольно много минусов и рисков его использования.

Показатели цитирования используются в качестве одного из критериев анализа деятельности российских вузов (качества высшего образования) при оценке их мест в ведущих мировых рейтингах (QS, THE и $\mathrm{ARWU}$, которые, необходимо отметить, малоприменимы для отечественных вузов). Уровень цитируемости научных публикаций является одним из основных показателей указанных рейтингов (его доля в указанных рейтингах составляет от $20 \%$ до $32.5 \%$ ). И именно этот показатель является одним из критериев, занижающих места российских вузов в международных рейтингах (на данный момент лишь немногое число ведущих вузов входит в мировые рейтинги, таких как МГУ, МФТИ, ВШЭ, Университет ИТМО, НИЯУ МИФИ, Казанский, Новосибирский, СанктПетербургский и Томский университеты, при этом места отечественных вузов довольно низкие - во вторую сотню вузов по оценке ТНЕ входит только МГУ, в третью сотню - МФТИ и ВШЭ [1]). Стремление повысить места, занимаемые российскими вузами в указанных рейтингах, и, 
соответственно, использование показателя цитируемости научных публикаций приводит к трансформации подходов к высшему образованию.

Также широкое распространение получила оценка исследовательской деятельности с использованием библиометрических показателей (показателей цитирования и связанной с ними статистикой), как наиболее «простых и объективных». Основные проблемы оценки результативности и эффективности деятельности научных организаций исследовались в работе [2]. Несмотря на то, что основные проблемы использования библиометрических показателей, такие как неполная, а иногда и искаженная оценка уровня и результатов научного исследования; неправильное толкование данных о цитировании при определении рейтинга журналов и статей, издающихся в них; возможность авторов влиять на значения индексов были описаны в 2015 г., использование этих показателей и индексов активно вводится в России.

Наиболее популярными являются индекс Хирша и импакт-фактор. Если первый показатель используют для оценки вклада конкретного ученого, то второй - для оценки научных журналов.

Индекс Хирша рассчитывается следующим образом: учёный имеет индекс $\mathrm{h}$, если $\mathrm{h}$ из его $\mathrm{Np}$ статей цитируются как минимум $\mathrm{h}$ раз каждая, в то время как оставшиеся $(\mathrm{Np}-\mathrm{h})$ статей цитируются не более чем h раз каждая.

Расчет импакт-фактора основан на трехлетнем периоде. Например, импакт-фактор журнала рассчитывается за 2019 г. таким образом:

ИФ $=\mathrm{A} / \mathrm{B}$

где A - число цитирований в течение 2019 года статей, опубликованных в данном журнале в 2018 и 2017 годах, в журналах, отслеживаемых Институтом научной информации; В - число статей, опубликованных в данном журнале в 2018-2017 годах [3, 4].

Однако, как было отмечено, оба показателя имеют недостатки. Так, индекс Хирша не отражает полностью научный вклад ученого, только вклад отдельной его статьи, число ссылок на которую может быть большим по разным причинам, например, это обзорная статья или попадающая в мейнстрим. Кроме этого значение индекса Хирша зависит от востребованности области и направления исследований, а также от импакт-фактора журнала, в котором напечатана статья.

Аналогично рейтингам вузов, большее количество ссылок получают статьи в области математики, при этом статьи в области гуманитарных наук - значительно меньше. 
Кроме этого необходимость повышения индекса Хирша приводит к значительному росту числа публикаций, что усложняет доступ к «качественным» научным работам. Также повышение значения индекса происходит с ростом самоцитирования и «дружественного» цитирования.

Необходимо отметить, что при расчете индекса не учитываются ссылки на главы книг и материалы конференции, что также ведет к искажению значения вклада ученого.

Еще одним недостатком индекса Хирша является то, что молодые ученые будут иметь более низкий индекс Хирша, что необходимо учитывать при оценке научного вклада. Для компенсации этого недостатка разработан т-индекс, который рассчитывается как отношение индекса Хирша ученого к числу лет, прошедших после первой публикации, однако т-индекс пока что мало распространен.

Активное использование индекса Хирша приводит к зависимости от цитирования, что приведет к увеличению «вылавливания цитат» (citation-fishing) и «цитатному обмену» (citation-bartering). При этом ограничение объема статей, что происходит во многих научных журналах, приводит к тому, что авторы начинают ссылаются не на первоисточники, а на статьи-обзоры, что значительно уменьшает показатели цитирования для статей-первоисточников и, соответственно, снижает научный вклад авторов статей-первоисточников.

Что касается недостатков импакт-фактора, можно выделить следующие:

- этот показатель оценивает всю совокупность статей, а не научную значимость конкретных опубликованных в журнале статей;

- у уровень цитирования также связан со спецификой области науки;

- значение импакт-фактора зависит от выбранного базового года расчета, особенно это касается журналов, которые выходят не регулярно или журналов, где возможно изменение числа статей в разные периоды - оно будет ниже в тех журналах, где статьи печатаются на нескольких языках;

- значение показателя в большой степени зависит от объема статьи (в журналах, где печатаются более короткие статьи, он ниже, чем в журналах, в которых печатаются статьи большего объема).

Активное использование импакт-фактора для оценки научного вклада приводит к сужению круга наиболее цитируемых авторов, что способствуют повышению импакт-фактора журнала за счет самоцити- 
рования и перекрестного цитирования. Также значение импакт-фактора может быть повышено за счет перекрестных ссылок между журналами.

Основная ошибка при использовании импакт-фактора журнала заключается в том, что его нельзя применять для оценки качества конкретной статьи, размещенной в соответствующем журнале, так как импакт-фактор оценивает именно журнал, а не качество научного текста. Необходимо понимать, что публикация в журнале с высоким уровнем импакт-фактора не является более качественной, чем статья, опубликованная в журнале с более низким значением этого показателя.

Указанные недостатки импакт-фактора и индекса Хирша приводят к росту числа статей в рецензируемых журналах, входящих в ВАК, Scopus и Web of Science, который увеличивает объемы поступающей информации и затрудняет ее анализ.

Так, проведенный анализ динамики числа российских публикаций в научных журналах, представленных в базах данных Scopus и Web of Science за 2000-2017 гг. (см. рис. 1), показывает, что до 2012-2013 гг. наблюдался небольшой рост публикаций в журналах, входящих в Scopus. При этом число статей в журналах Web of Science практически не изменялось. Однако после 2012-2013 гг. происходит значительный рост числа статей Scopus (практически в 2 раза). Это свидетельствует о начале внедрения оценки научного вклада через публикации, с акцентом на иностранные базы журналов, вызвавшей бурный рост числа статей в рецензируемых журналах, входящих в Scopus и Web of Science, что увеличивает объемы поступающей информации и затрудняет ее анализ.

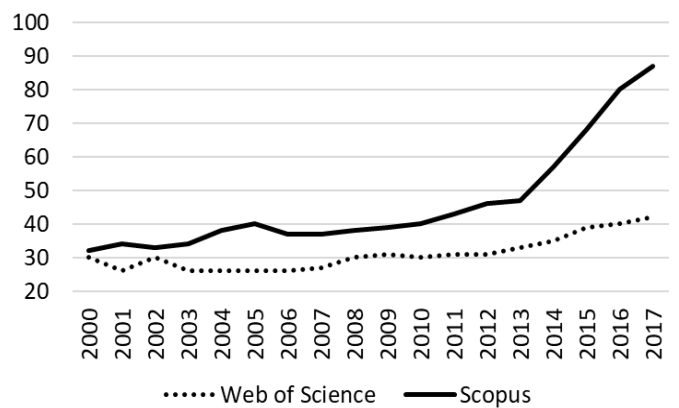

Рис. 1. Число публикаций России в научных журналах, представленных в БД Web of Science и Scopus в 2000 - 2017 гг. Источник: [5] 
Кроме возрастающих объемов информации, затрудняющих ее анализ, использование индекса Хирша и импакт-фактора приводит к следующим проблемам:

- снижение качества статей, публикуемых в рецензируемых журналах, что приведет к снижению ценности (с точки зрения индекса) других статей в этих журналах;

- деформация научной деятельности за счет отвлечение внимания и времени ученого на повышение собственного рейтинга в научном сообществе, что снижает качество статей;

- «нежелательный отбор» научных работ и увеличение их востребованности за счет высоких значений импакт-фактора соответствующих журналов и/или индекса Хирша авторов.

- перекос в распределении финансовых ресурсов.

Использование рассматриваемых показателей как инструментов оценки научного вклада ученых кроме указанных недостатков приведет к перекосу в распределении финансовых ресурсов, что приведет к усугублению указанных проблем и возможной потере научного потенциала. Таким образом, использование библиометрических показателей возможно только в качестве вспомогательного инструмента оценки результативности и эффективности науки. Деятельность исследователей необходимо оценивать, учитывая мнение научного сообщества, экспертов, выбираемых из его среды.

Активное бездумное внедрение показателей библиометрии как основы оценки результативности исследователей является одной из угроз дальнейшему развитию российской науки, что отмечалось отечественными учеными еще в 2014 г. [6]. 


\section{СПИСОК ЛИТЕРАТУРЫ}

1. Рейтинг вузов THE (2020 г.). URL:

https://www.timeshighereducation.com/world-university-rankings/2020/worldranking\#!/page/0/length/25/sort_by/rank/sort_order/asc/cols/stats

2. Варшавский A.E. Основные проблемы оценки результативности и эффективности деятельности научных организаций // Научно-практический журнал «Конщепщии».2015. № 1 (33). С. 3-8.

3. Robert Adler, John Ewing (Chair), Peter Taylor. Citation Statistics. 2008. URL: https://www.mathunion.org/fileadmin/IMU/Report/CitationStatistics.pdf

4. Rossner M., Van Epps H., Hill E. Show me the data // Journal of Cell Biology. 2007. Vol.179, no. 6. P.1091-1092. URL: http://jcb.rupress.org/content/179/6/1091

5. Наука, технологии и инновации России: крат. стат. сб. / [гл. ред. Л.Э.Миндели] — М.: ИПРАН РАН, 2017.

6. Варшавский А.Е. Проблемы развития государственного сектора науки в России // Научно-практический журнал "Конщепщии". 2014. №1 (32). С. 3-29.

\section{THE USE OF CITATION METRICS: ISSUES AND IMPLICATIONS}

\section{Nikonova M.A.}

Recently, bibliometric indicators - citation indexes (the Hirsch index and the impact factor) - have become widely popular for evaluating the contribution of scientists. In addition to their convenience (which is why they were chosen), they also have a number of disadvantages. Their active use can lead to significant problems over time. This article is devoted to the analysis of problems that may arise in situation of active use of bibliometric indicators. 